\title{
Auge y declive del referendo presidencial en Bolivia: antecedentes de la caída presidencial de Evo Morales
}

\section{Rise and decline of the presidential referendum in Bolivia: the background of the fall of Evo Morales}

Verónica Marlene Correa Flores

Recepción: 29-05-2020

Aceptación: 27-07-2020

\section{Resumen}

A lo largo de tres periodos presidenciales, Evo Morales Ayma ha convocado, por iniciativa propia, a cuatro Mecanismos de Democracia Directa a nivel nacional; de los cuales tres fueron aceptados por la población boliviana, mientras que el último fue rechazado. En el presente texto se analizará las condiciones de triunfo y un fracaso de estos mecanismos por parte del presidente boliviano, con la intención de explicar cómo el uso del referendo puede entenderse como un poder institucional del ejecutivo, el cual, al ser utilizado, puede resultar exitoso o fracasar cuando este poder se combina con factores contextuales como son el estado de la economía del país o la aprobación del presidente.

Palabras clave: Presidente, Democracia Directa, Referéndum, Clivaje Étnico.

\section{Abstract:}

Throughout three presidential terms, Evo Morales Ayma has convened, on his own initiative, four Direct Democracy Mechanisms at the national level, which three were accepted by the Bolivian population, while the last one was rejected. This work will analyze the conditions of triumph and an eventual failure of these mechanisms by the Bolivian president with the intention to explain how the use of the referendum can be understood as an institutional power of the executive, which, when used, can be successful or fail when this Power is combined with contextual factors such as the state of the country's economy or the approval of the President.

Key words: President, Direct Democracy, Referendum, Ethnic Cleavage. 


\section{Introducción}

$\mathrm{E}$

1 uso del referendo presidencial en los regímenes latinoamericanos ha sido objeto de controversia en los estudios académicos. Algunos autores como Gamble (1997), Lissidini (2005), Mayorga (2002) y Barzak (2003) sostienen que el presidente limita el juego institucional y obtiene ventaja al ser él quien propone convocar a las masas con una actitud plebiscitaria, y que el uso de estos mecanismos disminuyen la rendición de cuentas a nivel horizontal. Los trabajos arriba citados consideran que en las democracias de baja calidad resulta más fácil que los presidentes busquen ocupar mecanismos de democracia directa de tipo plebiscitario porque es probable que su posicionamiento político mejore, en tanto que se trate de referendos de corte institucional.

Por otra parte, existen otros autores que se centran en el aspecto normativo del uso del referéndum, como son los trabajos de Daniel Zovatto (2008), Francisco Soto Barrientos (2013). Finalmente, existe otra serie de trabajos como los de Breuer (2007), Altman (2010) Durán (2012), cuya orientación es más analítica, por lo que seleccionan diferentes variables para evaluar el éxito del referéndum y las consecuencias para la democracia. En esa serie de trabajos se distingue cuándo los referéndums son impulsados por el presidente y las diversas temáticas que abordan, así como si se trata de una consulta sobre temas estructurales o que atañen a una política pública, o si se trata de un referendo de carácter constitucional. En esa revisión analítica también se contempla la tradición democrática de los países o si éstos referéndums son impulsados por el poder ejecutivo, o si son organizaciones sociales las que lo impulsan.

Este artículo analiza el uso de referendo como una de las herramientas con las que cuentan los presidentes para ejercer el poder. La utilización del referendo asegura al presidente la oportunidad de salir al público y aumentar su popularidad, también considera que el referendo es una estrategia presidencial que busca prolongar el poder del presidente bajo dos condiciones: la primera, cuando logra que la convocatoria tenga éxito, es decir que la propuesta hecha por el presidente tenga el respaldo suficiente en las urnas, eso quiere decir, un alto nivel de participación y que la opción propuesta por el 
presidente sea la ganadora; bajo esas condiciones lo ratifica ante la opinión pública como el artífice de un cambio político sustantivo que se traduce en la implementación de alguna política pública o de un cambio institucional importante y la segunda, porque un éxito de esta naturaleza puede influenciar la permanencia del partido del presidente e incluso la reelección.

En este trabajo se analizarán las condiciones de triunfo y un eventual fracaso de estos mecanismos por parte del presidente boliviano con la intención de explicar cómo el uso del referendo puede entenderse como un poder institucional del ejecutivo, el cual al ser utilizado puede resultar exitoso o fracasar cuando se combina con factores contextuales como son el estado de la economía del país o la aprobacion del presidente.

De manera concreta "Por democracia directa se entiende aquí un grupo de instituciones políticas en las que los ciudadanos deciden o emiten su opinión en las urnas a través del sufragio universal y secreto y que no forma parte del proceso electivo regular de autoridades" (Altman, 2010). Estas instituciones han sido clasificadas en la literatura de la siguiente manera: referendo, plebiscito, e iniciativa ciudadana.

Las clasificaciones sobre la naturaleza de cada una de estas instituciones son diversas. Una primera clasificación nos ubica en la distinción de si éstos son convocados desde arriba (gobierno, constitución o poder legislativo), o si son convocados desde abajo, es decir a través de un número de firmas recabadas por los ciudadanos; otra clasificación distingue entre los Mecanismos de Democracia Directa (MDD) que son de naturaleza obligatoria (vinculantes) o si sólo son de consulta, también hay clasificaciones acerca de la temática del mismo, si se trata de una modificación constitucional o si versa sobre un tema de política pública (Durán, 2013).

David Altman se refiere a una clasificación basada en tres interrogantes: Quién es el iniciador, qué es lo que se persigue con un MDD y finalmente, si el MDD es la última palabra sobre una cuestión. A estas preguntas de Altman podrían sumarse dos nuevas preguntas: ¿el resultado del referendo tuvo los resultados esperados para el iniciador del proceso? Y ¿tuvo algún beneficio haber sido el impulsor del referendo? Por lo que podemos encon- 
trar que los actores involucrados inciden en la denominación de dichas instituciones, también es posible saber si su naturaleza es reactiva o proactiva de acuerdo con su naturaleza obligatoria o de consulta. Por su parte Altman (2010) los clasifica de la siguiente forma:

Referendos requeridos por la ley: éstos pueden ser convocados desde arriba, en ese caso se denominan plebiscitos, pueden servir para modificar una constitución completa o para una enmienda constitucional, también pueden consultar sobre cambios de la división administrativa del país o consultar sobre temas de gran relevancia económica para el país, como puede ser un tratado de libre comercio o sobre tratados internacionales. Pueden ser de naturaleza reactiva o proactiva.

También pueden ser convocados por la ciudanía para hacer alguna enmienda constitucional, y se denominan referendos, también pueden ser de manera reactiva o proactiva. En el mundo son identificados los casos de convocatoria ciudadana empleados por países como Suiza o Uruguay.

\section{Referendos impulsados por actores gubernamentales} (desde arriba): Pueden ser de manera vinculantes o no vinculantes. Cuando son proactivos se denominan plebiscitos, mientras que cuando son reactivos Altman los considera como una contrapropuesta legislativa. En el panorama latinoamericano este tipo de mecanismos están presentes en 11 de los 16 países que tienen en sus constituciones la figura del referendo y hay en Argentina, Bolivia, Brasil, Chile, Colombia, Costa Rica, Ecuador, Guatemala, Honduras, Paraguay y Venezuela

Iniciativas ciudadanas (desde abajo): Impulsados por la ciudadanía pueden también ser de naturaleza vinculante y no vinculante, cuando son proactivos se denominan iniciativa popular, cuando son reactivos se denominan referendo facultativo. Y cuando no son vinculantes se denominan iniciativas consultivas o referendo consultivo. 
Esta clasificación es la que se considera adecuada para la selección de los casos de estudio que se analizarán en este trabajo. La hipotesis de este trabajo busca probar que el éxito de los referendos presidenciales en Bolivia fueron producto de los poderes constitucionales y partidarios del presidente, de su popularidad, y de la capacidad de movilizar el voto, incluso en contextos de polarización política.

\section{Los MDD en Bolivia}

Para entender como la celebración de consultas populares se ha popularizado en Bolivia es necesario considerar que el uso de estos mecanismos de democracia direcra en la región de América Latina se ha triplicado en las dos últimas tres décadas (Welp, 2010:27). A partir de una revisión panorámica es posible constatar que las constituciones latinoamericanas contienen una gran diversidad en lo que se refiere a la utilización de MDD y particularmente en el uso del referendo. Dentro de estas prácticas sobre el uso de MDD destaca el impulso de referendos por parte del poder ejecutivo, pues no sólo son más recurrentes, sino que además han obtenido mayor difusión y despertado mayor interés académico. Tal como refiere Francisco Soto Barrientos, desde 1985 a septiembre de 2017 se han producido 20 referendos, de los cuales 15 están concentrados en los últimos diez años, y pese a que la referencia obligada cuando se habla de democracia directa es Uruguay, lo cierto es que el mayor número de eventos durante los últimos años ha estado concentrado en la región andina, de forma específica, siete referendos en Ecuador, Bolivia y Venezuela, aunque Colombia y Perú también han celebrado referendos.

Sobre el caso boliviano, vale la pena destacar que en el año 2002, “el Congreso aceptó reformar la Constitución abriéndola al referéndum y a la niciativa ciudadana para plantear proyectos de ley al Parlamento (los cambios no entraron inmediatamente en aplicación pues necesitaban ser ratificados por la siguiente legislatura, lo que sucedió en el 2004) (Romero, 2008). Cuando el vicepresidente Carlos Mesa asumió el poder el 17 de octubre de 2003 la presión popular logró imponer una serie de demandas denominadas como la Agenda de Octubre, ésta tenía como objetivo: - la revisión de la ley de hidrocarburos, convocatoria a referéndum consultivo para definir una política de gas y convocatoria de la Asamblea Constituyente (Romero, 2008). 
La reforma a la constitución, llevada a cabo en febrero de 2004, incluyó entre los aspectos más significativos la inclusión de algunas instituciones de la democracia directa como son: el referéndum, la iniciativa legislativa ciudadana y la normatividad para la creación de una asamblea constituyente.

A lo largo de tres periodos presidenciales, que abarcaron del 22 de enero de 2006 al 10 de noviembre de 2019, Evo Morales Ayma convocó por iniciativa propia, a cuatro Mecanismos de Democracia Directa a nivel nacional (véase cuadro 1).

\section{Cuadro1 Referéndums presidenciales Evo Morales 2006-2016}

\begin{tabular}{|c|c|c|c|c|}
\hline $\begin{array}{l}\text { Mecanismo de de- } \\
\text { mocracia directa }\end{array}$ & Fecha & Convocado por: & Resultados & $\begin{array}{l}\text { La opción } \\
\text { presidencial }\end{array}$ \\
\hline $\begin{array}{l}\text { Referendo vincu- } \\
\text { lante a la Asamblea } \\
\text { Constituyente por } \\
\text { las autonomías } \\
\text { departamentales }\end{array}$ & $\begin{array}{l}6 \text { de julio de } \\
2006\end{array}$ & Congreso & $\begin{array}{c}\text { MAS } 53 \% \\
\text { PODEMOS } \\
23.5 \% \\
\text { OTROS } \\
22.7 \%\end{array}$ & Ganó \\
\hline $\begin{array}{l}\text { Referéndum revo- } \\
\text { catorio }\end{array}$ & $\begin{array}{l}10 \text { de agosto } \\
\text { de } 2008\end{array}$ & $\begin{array}{l}\text { Congreso Nacio- } \\
\text { nal, impulsado } \\
\text { en el Senado por } \\
\text { PODEMOS }\end{array}$ & $\begin{array}{l}\text { Sí } 67 \% \\
\text { No } 33 \%\end{array}$ & Ganó \\
\hline $\begin{array}{l}\text { Referéndum consti- } \\
\text { tucional }\end{array}$ & $\begin{array}{l}25 \text { de enero } \\
2009\end{array}$ & $\begin{array}{l}\text { Congreso Nacio- } \\
\text { nal Boliviano }\end{array}$ & $\begin{array}{l}\text { Sí } 61.4 \% \\
\text { No } 38.57\end{array}$ & Ganó \\
\hline $\begin{array}{l}\text { Referéndum cuarto } \\
\text { periodo presidencial } \\
\text { (reelección) }\end{array}$ & $\begin{array}{l}21 \text { de febrero } \\
2016\end{array}$ & $\begin{array}{c}\text { Congreso Nacio- } \\
\text { nal Boliviano }\end{array}$ & $\begin{array}{l}\text { Sí } 48.7 \\
\text { No } 51.3\end{array}$ & Perdió \\
\hline
\end{tabular}

Fuente: Elaboración propia con datos de la Corte Nacional Electoral

Se pondrá especial énfasis en explicar cómo se iniciaron los procesos de convocatoria, las condiciones políticas y actores que intervinieron en el diseño de las preguntas de los referéndums, así como algunos factores contextuales que pudieron influir sobre los resultados, sobre todo el referente al apoyo de asociaciones o grupos de apoyo a la opción presidencial, así como algunos factores de corte económico. 
En particular se ofrece una explicación sobre cómo en las convocatorias presidenciales de Evo Morales se acentuaban los conflictos de división étnica y cómo estos constituyeron un elemento de éxito o fracaso en cuanto a las condiciones en las que se presentaron esos referéndums.

Durante los dos primeros periodos de gobierno de Evo Morales (2006 y 2010), la apuesta por el cambio político y el apoyo popular fueron las banderas con las que el presidente había conducido su gobierno, desde que contendió por primera vez por la presidencia de la República, el candidato cocalero tenía la propuesta más radical en su discurso, pues proponía un plan nacionalista antineoliberal "centrado en la denuncia de los efectos de la privatización implementadas desde 1985 y en el rechazo al sometimiento nacional a las empresas transnacionales y el 'imperio' (específicamente a E.U.)" (Stefanoni, 2010:8). Este discurso se mantuvo una vez en el gobierno, lo que le ha generado toda clase de simpatías y antipatías al interior y al exterior de Bolivia.

La propuesta de Morales se suma a la propuesta de otros presidentes de la región como era el venezolano Hugo Chávez o Rafael Correa de Ecuador, que buscaban presentar un modelo alternativo políticamente y que se denomina como izquierda bolivariana y que sumaba a los presidentes de Venezuela y Ecuador, sin embargo, la postura radical de Morales agudizó el clivaje étnico ${ }^{1}$ y económico, lo que en determinados momentos ha puesto en tensión el régimen del Movimiento al Socialismo (MAS), sobre todo en el margen de la lucha por las autonomías regionales, o frente a la postura del propio Evo Morales con los medios de comunicación.

Pese a esta agudización del conflicto derivado por las divisiones étnicas y económicas del país, la oposición política al MAS estuvo desarticulada durante largo tiempo, la causa más evidente de esta desarticulación es la desaparición del sistema de partidos tradicional que se mantuvo durante el periodo denominado como la Democracia Pactada de 1982 a 2003, Romero Ballivián explica como "en Bolivia existen partidos, pero ha desaparecido el sistema de partidos, entre 2002 y 2014, únicamente el MAS ha tenido presencia en los cuatro procesos presidenciales, todos los demás han desaparecido,

1 El término clivaje proviene del anglicismo cleavage que se refiere a un quiebre o fragmentación. 
participan de manera intermitente o recién comienzan” (Romero, 2014:148).

Romero Ballivian sugiere que parecía no existir la voluntad política desde el gobierno del Morales por reconstruir el sistema de partidos, "Para el MAS, recomponerlo significaba fortalecer a una oposición dispersa y desarticulada" (Romero, 2014:148), por lo que es notable como los partidos que conformaban el sistema de partidos tradicionales, no sobrevivieron al cambio de régimen político después de la llegada de Evo Morales, en la tabla 2 es posible notar que el Movimiento Nacional Revolucionario fue el único partido que contendió en 2005, mientras que el Partido Democráta Cristiano revivió en la elección de 2014 (Véase cuadro 2).

En la misma tabla es posible notar que existe un sistema multipartidista, sin embargo los nuevos partidos políticos no han podido consolidarse como una fuerza política efectiva, capaz de desplazar al MAS, prueba de ello es que los porcentajes de votación de los partidos políticos con respecto al ganador son muy bajos, asimismo al calcular el número efectivo de partidos (NEP) siguiendo la fórmula de Laakso y Taagepera (1979), fue posible identificar que se ha reducido el número efectivo de partidos al pasar de 5 partidos en la primera legislatura en 2002 a la de 1.9 en 2014 (Véase cuadro 3). 


\section{Cuadro 2}

Resultados electorales presidenciales, porcentajes por partido político

\begin{tabular}{|c|c|c|c|}
\hline Antes de Evo Morales & \multicolumn{3}{|c|}{ Después de Evo Morales } \\
\hline $\begin{array}{c}\text { Sistema de Partidos } \\
\mathbf{2 0 0 2}\end{array}$ & $\begin{array}{c}\text { Sistema de Parti- } \\
\text { dos 2005 }\end{array}$ & $\begin{array}{c}\text { Sistema de par- } \\
\text { tidos }\end{array}$ & Sistema de Partidos \\
\hline ADN 3.4 & 2009 & 2014 \\
UCS-FSB 5.5 & MNR 6.5 & MAS 64.2 & PDC 9.0 \\
PS 0.7 & MAS 53.7 & UN-CP 5.7 & MAS 61.4 \\
MNR-MBL 22.5 & FREPAB 0.3 & PPB-CN 26.5 & PVB-IEP 2.7 \\
MIR-NM-FRI 16.3 & UN 7.8 & BSD 0.2 2.7 \\
CONDEPA-MP 0.4 & MIP 2.2 & MUSPA0.5 & UD. 24.2 \\
NFR 20.9 & PODEMOS 28.6 & AS 2.3 & \\
MAS, 20.9 & NFR 0.7 & PULSO0.3 & \\
MIP 6.1 & USTB. 0.3 & & \\
MCC 0.6 & & & \\
\hline
\end{tabular}

Fuente: Elaboración propia con base en Atlas Electoral de Bolivia 2010

\section{Cuadro 3}

Número Efectivo de Partidos de 2002 a 2014

\begin{tabular}{|c|c|c|c|c|}
\hline AÑO & 2002 & 2005 & 2009 & 2014 \\
\hline NEP Diputados & 4.9 & 2.3 & 1.8 & 1.9 \\
\hline NEP Senado & 3.3 & 2.3 & 1.6 & 1.8 \\
\hline
\end{tabular}

Fuente: Elaboración propia con base en los resultados del Atlas Electoral de Bolivia 2014

Esta característica del sistena de partidos puso en riesgo el compromiso democrático del régimen por lo que la opción del MAS fue privilegiar los vínculos con los movimientos sociales que le eran afines antes que con las otras organizaciones partidarias, lo que quedó de manifiesto cuando se 
revisan la integración de los gabinetes presidenciales de Evo Morales donde al menos catorce de los secretarios de estado eran líderes campesinos, vecinales, sindicales y líderes sociales. Por su parte, la oposición buscaba acrecentar su fuerza desde lo local sin tener una presencia significativa (Ballivián, 2019:148), por lo menos hasta las elecciones de 2019, cuando se conformó una fuerza capáz de movilizar el voto en contra del régimen.

Pese a que Morales pudo mantener su hegemonía desde el año 2006 hasta el año 2019 en que se produjo su salida de la presidencia de Bolivia de forma precipitada, después de su tercer intento de reelegirse a la presidencia, el declive de su poder comenzó cuando éste buscó legitimarse a través de un referendum presidencial impulsado en 2016 en donde se consultaba a la población sobre su reeleción a la presidencia en las elecciones de 2019, el resultado no le fue favorable, pues no consiguió ganar su propuesta, por lo que este suceso lo llevó a una toma de desiciones erraticas.

\section{De la Asamblea Constituyente al Referéndum constitucional}

La refundación del Estado a través de una Asamblea Constituyente (AC) se convirtió en la bandera con la que el MAS arribó al poder. Evo Morales fue electo como presidente constitucional de Bolivia en diciembre de 2005 con la mayoría absoluta de los votos (53.7\%), lo que representaba un hecho significativo pues la última vez que un presidente había obtenido esos resultados fue en el año de $1982^{2}$; además del inédito apoyo popular que tuvo el presidente al ganar la elección presidencial, el partido MAS se convirtió en la primera fuerza con 72 diputados, sin embargo en el Senado no logró tener la mayoría, aun así era la segunda fuerza.

Para Mark Clarence Walker (2003), la estrategia que siguen los presidentes que convocan a referéndums está condicionada por la negociación entre las élites, es relevante que para el caso boliviano lo que precedió a la estrategia presidencial de Evo Morales para convocar por primera vez a un referéndum, es la ruptura de esos pactos entre las élites que habían dominado desde 1985 hasta 2003, ese periodo fue conocido como Democracia Pactada

2 El sistema político boliviano se caracterizó durante los años 1985 y 2002 por tener un sistema de partidos altamente fragmentado que funcionaba a partir de la creación de pactos políticos que giraban en torno a las tres fuerzas políticas más importantes. 
(Lanzaro, 2001; Mayorga, 2001; Correa, 2011). Evo Morales había fincado su estrategia en su liderazgo sustentado en popularidad y en sus poderes partidarios, así como en las condiciones económicas favorables de ese momento y soslayando los acuerdos con la oposición, sin embargo, durante el desarrollo de la convocatoria y conformación de la Asamblea Constituyente, el propio Morales se vio obligado a negociar algunos aspectos con la oposición. Fernando Mayorga (2019) explica como el proceso constituyente "exigió el despliegue de otros recursos de poder y otras estrategias discursivas por parte del presidente y la coalición de gobierno en un contexto político-institucional que se caracterizó por un esquema político que combinaba una figura de gobierno dividido y pugna vertical de poderes".

La llegada de Evo Morales al poder puso en evidencia una serie de conflictos regionales y de naturaleza étnica que se hallaba en estado latente en Bolivia, pese a que el MAS había ganado con un amplio margen la presidencia, la conformación de gobiernos locales, por primera vez en 2006, había otorgado protagonismo a los prefectos departamentales, fueron éstos quienes se convirtieron en la verdadera oposición al régimen de Morales, por lo que existe la distinción entre los departamentos denominados como la Media Luna -Santa Cruz, Beni, Pando, Chuquisaca y Tarija- y los del occidente boliviano -La Paz, Oruro, Potosí. Cabe señalar que si bien Cochabamba está en el centro del país algunos autores como María Teresa Zegada (2016) han considerado como parte de ese bloque occidental; la "Media Luna" concentra el área urbana y el sector empresarial y de mayor empuje económico.

Para explicar la naturaleza del clivaje étnico boliviano, hay que entender que éste se encontraba subyacente en las relaciones políticas durante la democracia pactada, y que fue con la caída de los partidos tradicionales durante la crisis política de 2002 a 2005 y el resurgimiento de partidos indigenistas como el MAS que el clivaje étnico cobró mayor fuerza. Durante la época correspondiente a la democracia pactada, los partidos políticos fueron incapaces de organizar las identidades socio- políticas de la población, a decir de Mariana Giustti Rodríguez, en el contexto boliviano "se sugiere que la ausencia de un sistema de partidos consolidado es producto de la falta de clivajes sociales con suficiente fuerza para estructurar las identidades políticas de la población. Al contrario, lo que se observa en Bolivia es un ciclo inter- 
minable de construcción y fracaso de nuevos vehículos políticos” (2014:24).

Pese a que el clivaje etnico representaba un obstáculo para la toma de decisiones, una serie de factores propiciaban un ambiente económico positivo para convocar, no sólo a la conformación de la asamblea constitucional, sino también para aceptar un referéndum revocatorio de mandato y para ratificar la constitución política de Bolivia.

Como ya he señalado, a partir de estas condiciones tanto políticas como económicas es que Morales optó por impulsar la ley de Convocatoria para la integración de la Asamblea Constituyente. Las demandas para elaborar una nueva constitución no eran exclusivas del MAS, sin embargo, una vez llegado a la presidencia, Evo Morales respondió con la conformación de una asamblea Constituyente (AC). La ley especial de Convocatoria a la Asamblea Constituyente y referéndum vinculante estableció que "la 'única finalidad' de la AC era la 'reforma total' de la Constitución Política del Estado, fijando un periodo de sesiones no menor de seis meses mi mayor a un año, a partir del día su instalación" (Lazarte, 2008). También señalaba que la AC aprobaría el texto de la nueva Constitución con dos tercios de los votos de los miembros presentes en la Asamblea.

Concluida la misión de la Asamblea Constituyente, el Poder Ejecutivo convocará a Referéndum Constituyente, en un plazo no mayor a ciento veinte días a partir de la convocatoria. En dicho Referéndum, el pueblo boliviano refrendará, por mayoría absoluta de votos, el proyecto de la nueva Constitución en su totalidad, propuesto por la Asamblea Constituyente (Corte Nacional Electoral, 2006:3)

Un elemento importante que prescribió la Ley de Convocatoria a la Asamblea Constituyente era que la AC "es independiente y ejerce la soberanía del pueblo. No depende ni está sometida a los poderes constituidos y tiene como única finalidad la reforma total de la Constitución Política del Estado" (Ley de Convocatoria, 2006). Este señalamiento, conocido como la regla de dos tercios, fue motivo de fuertes disputas entre el oficialismo y las fuerzas opositoras. 
El referendo vinculante a la Asamblea Constituyente por las autonomías departamentales

La convocatoria fue recibida con entusiasmo, numerosas organizaciones políticas, sociales e indigenistas manifestaron su intención de participar en la elección que se celebró el día 6 de julio de 2006. Los resultados favorecieron al MAS que obtuvo un total de 137 puestos "distribuidos entre militantes del partido, intelectuales y líderes de diferentes organizaciones" (Deheza, 2007:50). El segundo lugar lo ocupó PODEMOS con 60 puestos; los demás puestos fueron distribuidos en 14 asociaciones políticas y sociales diversas (véase cuadro 4).

Cuadro 4. Asamblea Constituyente: número de escaños

\begin{tabular}{|c|c|c|c|}
\hline Sigla & Departamentales & $\begin{array}{c}\text { Circunscripciones uni- } \\
\text { nominales }\end{array}$ & Totales \\
\hline AAI & 0 & 1 & 1 \\
\hline APB & 1 & 2 & 3 \\
\hline AS & 1 & 5 & 6 \\
\hline ASP & 1 & 1 & 2 \\
\hline AYRA & 0 & 2 & 2 \\
\hline $\mathrm{CN}$ & 2 & 3 & 5 \\
\hline MAS & 18 & 119 & 137 \\
\hline MBL & 1 & 7 & 8 \\
\hline MCSFA & 0 & 1 & 1 \\
\hline MIR-NF & 1 & 0 & 1 \\
\hline MNR & 3 & 5 & 8 \\
\hline MNR-A3 & 1 & 1 & 2 \\
\hline MNR-FRI & 1 & 7 & 8 \\
\hline MOP & 1 & 2 & 3 \\
\hline PODEMOS & 11 & 49 & 60 \\
\hline UN & 3 & 5 & 8 \\
\hline TOTALES & 45 & 210 & 255 \\
\hline
\end{tabular}

Fuente: Elaboración propia con datos de la Corte Nacional Electoral 
En esa misma Ley que convocaba a la celebración de un referéndum con carácter vinculante a la Asamblea Constituyente se definiría la postura de los ciudadanos sobre transformación de los departamentos en regiones autónomas. Esta demanda fue encabezada por movimientos cívicos y grupos empresariales de los departamentos del oriente boliviano desde 2005, pero tuvo efecto hasta el 6 de julio de 2006 junto con la elección de la Asamblea Constituyente.

La pregunta que se formuló para el referéndum autonómico es la siguiente:

¿Está usted de acuerdo, en el marco de la unidad nacional, en dar a la Asamblea Constituyente el mandato vinculante para establecer un régimen de autonomía departamental, aplicable inmediatamente después de la promulgación de la nueva Constitución del Estado en los Departamentos en donde este referéndum tenga mayoría, de manera que sus autoridades sean elegidas por los ciudadanos y reciban del Estado Nacional competencias ejecutivas, atribuciones normativas administrativas y los recursos económicos que le asigne la nueva Constitución Política del Estado y las leyes? (Corte Nacional Electoral, Referéndum 2006).

De acuerdo a la convocatoria, las autonomías serían aprobadas, respectivamente en cada departamento, si la respuesta "sí" obtenía la mayoría simple; la convocatoria también estipulaba que los departamentos que así lo aprobaran accederían a las autonomías una vez aprobada la nueva Constitución (véase cuadro 5).

\section{Cuadro 5}

\begin{tabular}{|c|c|c|}
\hline Respuesta & Votos obtenidos & Porcentaje \\
\hline Sí & $1,237,312$ & $42.412 \%$ \\
\hline No & $1,680,329$ & $57.588 \%$ \\
\hline Total válidos & $2,917,329$ & $100 \%$ \\
\hline
\end{tabular}

Fuente: Elaboración propia con datos de la Corte Nacional Electoral

Los resultados del referéndum mostraron nuevamente una sociedad 156 
dividida: cinco departamentos votaron por el "NO": La Paz, Oruro, Cochabamba y Potosí que apoyaban la postura del MAS, mientras que el "SÍ' venció en Santa Cruz, Pando, Beni y Tarija. Los resultados positivos en el oriente boliviano fueron anulados cuando el gobierno del MAS interpretó los resultados a nivel nacional y no por departamento, tal como explicaba la ley de convocatoria, y declararon que no habría autonomías. Esta determinación generaría fuertes conflictos en los trabajos de la AC.

Durante varios meses la discusión sobre las autonomías paralizó el trabajo de la AC, sobre todo por la falta de disposición del oficialismo a la concertación con otras organizaciones políticas. "Este impase derivó en una fractura entre el oficialismo, entonces la oposición se trasladó a espacios no institucionales a través de paros cívicos, huelgas de hambre, e inclusive graves enfrentamientos entre civiles. El resultado fue el mantenimiento de lo establecido en la ley de convocatoria" (Mayorga, 2008:37).

Una de las líneas de debate más importante que se generó en la AC, fue la discusión sobre la descentralización política del Estado a través de las autonomías. Mientras que los departamentos orientales exigían el cumplimiento del referéndum sobre las autonomías, mediante cabildos públicos, el MAS planteó un nuevo modelo de Estado Plurinacional, en esta propuesta "se expresan los matices indigenistas y la apelación a las nacionalidades indígenas y originarias (Mayorga, 2008)". En oposición, la propuesta presentada por PODEMOS, proponía un modelo de autogobierno departamental con competencias normativas plenas.

Después de esta parálisis, y ausencia de diálogo democrático, a finales de octubre "se organizó un consejo suprapartidario bajo el auspicio de la Vicepresidencia de la República con la participación de las 16 fuerzas constituyentes y se encaró la tarea de conciliar posiciones en torno a los principales temas de controversia" (Mayorga, 2008:37). El acuerdo al que se llegó fue que la Constitución reconocía cuatro tipos de autonomía: municipal, departamental, regional e indígena, ésta última será reconocida en el ámbito municipal; en cuanto a las autonomías regionales serían aprobadas por los futuros gobiernos departamentales. 
La Constitución fue aprobada en la AC sin la presencia de la oposición el 9 de diciembre de $2007^{3}$. Posteriormente, la constitución aprobada fue remitida al Congreso para la emisión de la ley de convocatoria del referéndum que debía aprobar o rechazar la nueva constitución política. En febrero de 2008, el Congreso Nacional con dos tercios de los congresistas del partido oficialista, y sin el apoyo minoritario de la oposición, aprobó el llamado a refrendar la Constitución para el 4 de mayo.

\section{El referendo revocatorio}

En medio de las disputas políticas por la ratificación de la Constitución y la lucha por las autonomías, se impulsó un referéndum revocatorio de mandato, aunque originalmente la iniciativa fue presentada por la oposición, de forma específica por PODEMOS, el gobierno de Morales decidió impulsar la ley de convocatoria para que se llevara el referéndum, y la oposición se sumó para aprobarla.

La base de apoyo que Morales tenía en los sectores populares le sirvieron para promulgar un referéndum revocatorio de mandato. El líder cocalero hizo un cálculo de los beneficios de apelar al apoyo de las masas y ratificar su poder, mientras que la actitud de la oposición parecía improvisada pues hizo un mal cálculo al apostar a una posible pérdida del presidente. La ley del referéndum revocatorio establecía las reglas para poder revocar al Presidente y Vicepresidente si la votación en contra alcanzaba un porcentaje mayor a la votación de la elección presidencial, por lo que el porcentaje de NO tenía que ser de más del 53.74 más uno por ciento, en el caso de los prefectos, la revocatoria de su mandato dependía de que la votación por el NO superara sus porcentajes de votación en las elecciones del 18 de diciembre de 2005. Finalmente, la organización política PODEMOS aprobó en el Senado por mayoría la ley 3850 del Referéndum Revocatorio de Mandato Popular el día 8 de mayo de 2008, dicha ley fue promulgada el día 12 de mayo.

Las campañas dieron inicio el 9 de junio de 2008 en medio de un clima de inconformidad por algunos prefectos que consideraban que la ley

3 Los eventos que encerraron la negociación de la Nueva Costitución Política del Estado estuvieron implican una narrativa amplia que no será abordada en este texto, para mayor referencia véase (Pachano, 2019). 
era inequitativa y ambigua, las principales críticas se dirigían a cuestionar el hecho de que los porcentajes requeridos estaban sustentados en una votación del año 2005, y que para el año de celebración del referendo el padrón electoral había aumentado. Otro de los puntos señalados por la oposición al MAS, era que la elaboración de las preguntas, establecía claras diferencias entre la pregunta dirigida para ratificar al presidente y la pregunta dirigida para ratificar a los prefectos. Las preguntas tenían esta redacción:

En el caso del Presidente la pregunta fue enunciada de la siguiente manera: ¿Usted está de acuerdo con la continuidad del proceso de cambio liderizado (sic.) por el Presidente Evo Morales Ayma y el Vicepresidente Álvaro García Linera? En el caso de los Prefectos la pregunta era: ¿Usted está de acuerdo con la continuidad de las políticas, acciones y gestión del Prefecto del Departamento? (OEA, 2009:6).

A estas inconformidades de las prefecturas y de las cortes departamentales se sumaron los señalamientos de la Corte Nacional Electoral que también señaló las posibles dificultades sobre el marco regulador de los porcentajes y sobre las preguntas del Referéndum.

"El día 31 de julio, la Corte Nacional Electoral (CNE) junto con siete Cortes Departamentales (excepto Oruro y Santa Cruz) emitió a través de la resolución No 123/2008 una disposición sobre los criterios de aplicación técnica para el conteo del Referéndum buscando así clarificar los criterios establecidos por la Ley de Referéndum, según esta resolución, para que un Prefecto fuese revocado tendría que obtener un voto en contra superior al 50 por ciento más uno. En el caso del Presidente, para que fuera revocado tendría que obtener un voto en contra superior al 53.7 por ciento más uno" (OEA, 2009:6).

La resolución que expidió la $\mathrm{CNE}$, en realidad no era ni interpretativa, ni modificaba el referéndum, el argumento que presentó en su momento José Luis Exeni, era que la Corte Nacional Electoral podía establecer criterios técnicos. Esta nueva disposición fue puesta en controversia por los prefectos, quienes consideraban que las modificaciones eran ilegales pues los criterios 
sólo tendrían que haberse modificado por el Congreso, toda vez que ahí se había promulgado la ley, esta situación provocó desconcierto entre la prensa. Esta contradicción podría poner en riesgo la celebración del referendo, no obstante, se llevó a cabo. Las semanas que antecedieron al referendo estuvieron llenas de acontecimientos de protesta, huelgas de hambre e inconformidad en los departamentos ${ }^{4}$. Este tipo de respuestas por parte de la Corte Nacional Electoral explican en débil control judicial de Bolivia, lo que pone en una situación de ventaja al poder ejecutivo al momento de que las interpretaciones de las instituciones electorales o judiciales son parciales o tienen poca capacidad para incidir en la regulación de los referendos.

Prueba del apoyo que ciertos sectores brindan al gobierno del MAS quedó de manifiesto en la respuesta positiva al referéndum de revocación de mandato, que se celebró en Bolivia el 10 de agosto de 2008, para decidir sobre la permanencia del Presidente y de ocho de los nueve prefectos departamentales (véase gráfica 1 y cuadro 6)

\section{Gráfica 1. Resultados del referéndum revocatorio popular}

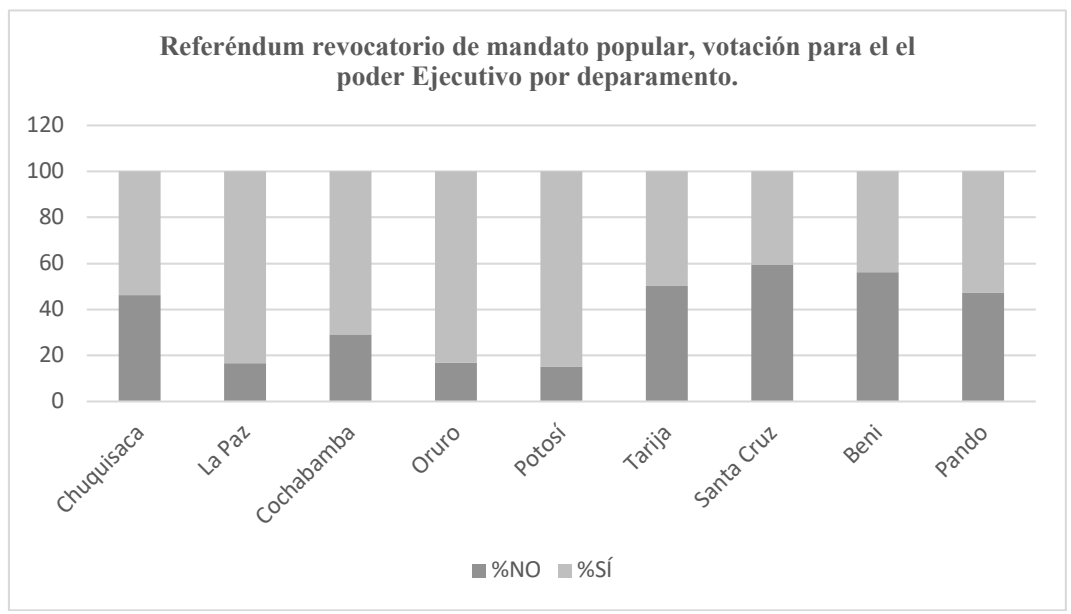

4 La Central Obrera Boliviana (COB) se movilizó desde el 21 de julio, demandaban la aprobación del proyecto de ley de pensiones elaborado por la misma Central. El gobierno rechazó el proyecto, por lo que hubo fuertes enfrentamientos y cerco a ministerios en la ciudad de La Paz. El 4 de agosto, faltando seis días para la celebración del Referéndum se inició una huelga de hambre en los seis departamentos. 


\section{Cuadro 6. Resultados del Referéndum Revocatorio Popular}

\begin{tabular}{|l|l|l|l|l|l|l|l|l|l|}
\hline $\begin{array}{l}\text { R e s - } \\
\text { puesta }\end{array}$ & $\begin{array}{l}\text { C h u - } \\
\text { quisa- } \\
\text { ca }\end{array}$ & La Paz & $\begin{array}{l}\text { Cocha- } \\
\text { bamba }\end{array}$ & Oruro & Potosí & Tarija & $\begin{array}{l}\text { S a n t a } \\
\text { Cruz }\end{array}$ & Beni & Pando \\
\hline No & 46.12 & 16.73 & 29.1 & 17 & 15.13 & 50.17 & 59.25 & 56.28 & 47.5 \\
\hline Sí & 53.88 & 83.27 & 70.9 & 83 & 84.87 & 49.83 & 40.75 & 43.72 & 52.5 \\
\hline
\end{tabular}

Fuente: Elaboración propia con datos de la CNE.

El resultado ratificó la permanencia de Evo Morales en el poder al obtener $67 \%$ de votos a su favor. Es evidente que el presidente mantuvo la base de apoyo social que lo llevó a la presidencia, pero también es contundente el rechazo del $43 \%$ de los ciudadanos que no apoyaban el gobierno de Morales. Pese a los señalamientos de la Corte Nacional Electoral, el presidente logró imponer la pregunta pues los actores no tuvieron capacidad para imponer cambios importantes al contenido de la misma.

\section{Aprobación del referendo constitucional}

Las continuas confrontaciones entre simpatizantes del MAS y grupos autonomistas durante el 2008, así como la falta de acuerdo en el Congreso para convocar al referéndum constitucional, demostraban el impase entre la oposición y el oficialismo y la ausencia de consensos. Apoyado en su popularidad, de acuerdo con datos del Latinobarometro durante el año 2009 la aprobación al gobierno era del 67 por ciento, el gobierno de Morales ha evitado los consensos y ha optado por vías alternativas sin observancia de la ley, ejemplo de ello fue la emisión de un decreto presidencial para convocar al referéndum constitucional, mismo que fue rechazado por la Corte Nacional Electoral.

Fue durante octubre, que la oposición y el oficialismo buscaron un acuerdo $^{5}$ para viabilizar la celebración del referéndum para la ratificación de

\footnotetext{
5 "Para la culminación positiva del acuerdo se produjo una combinación de factores, entre los cuales sobresale la circunscripción del proceso decisional a un escenario institucional como el Congreso y conformado por un delimitado conjunto de actores políticos que conformaron una "mesa clandestina" que actuó en paralelo a la comisión multipartidaria congresal" (Pachano, 108:2019), así pues Evo Morales tuvo que negociar con la oposición algunos aspectos como fue la exensión de los latifundios, pues además de responder si estaban de acuerdo o no con la Constitución se les consultó a los electores sobre la cantidad de tierra que podrían acumu-
} 
la Constitución. El referéndum fue celebrado el día 25 de enero de 2009. La constitución fue aprobada con el $61.43 \%$ de votos positivos.

La campaña electoral para la celebración del referéndum tuvo una duración de sesenta días. Los actores políticos involucrados fueron el Partido político en el gobierno, El movimiento al Socialismo (MAS), que era el principal defensor de la Constitución Política del Estado (CPE). A la campaña por el SÍ también se unió la Coordinadora Nacional para el Cambio (CONALCAM) que estaba integrada por varios movimientos sociales. También se unieron positivamente a la campaña algunas agrupaciones campesinas y sindicales como: La Confederación Sindical Única de Trabajadores de Bolivia (CSUTB), la Central de Indígenas del Oriente de Bolivia (CIDOB), Central Obrera Bolivariana (COB), Federación de Mujeres Campesinas Bartolina Sisa y el Consejo Nacional Ayllus y Markas del Qollasuyo (CONAMAQ). Una constante en el ejercicio de los referéndums latinoamericanos, y en este caso particular de Bolivia es la capacidad que tiene el presidente o la oposición para formar coaliciones políticas en las que participan asociaciones o movimientos civiles que ejercer la labor de movilizar el voto.

Por otra parte, la campaña del No estaba conformada por algunas organizaciones ubicadas principalmente en la "Media Luna". El Consejo Nacional Democrático (CONALDE) estaba integrada por los prefectos y comités cívicos de los departamentos Santa Cruz, Tarija, Beni y Chuquisaca. En el Congreso el partido PODEMOS era el principal opositor del partido del presidente, sin embargo había posiciones encontradas con respecto a la CPE, mientras que algunos se posicionaban por el Sí, como era el senador Carlos Borth, el presidente del partido Jorge Quiroga se opuso al proyecto constitucional faltando escasos días del referéndum. Los demás partidos opositores al MAS, Unidad Nacional (UN) Movimiento Nacional Revolucionario (MNR) que tenían una escasa representación política se opusieron a la CPE.

La campaña empezó oficialmente el día 23 de noviembre de 2008, la campaña se concentró de manera más visible en los centros urbanos. Los lemas de campaña eran "Sí" o "No" a la CPE. La figura representativa del Sí

1ar los ciudadanos, pero donde quedaba de manifiesto que no afectaría a quienes en el pasado habían adquirido grandes extensiones de tierra, por lo que con esta decisión no se afectó a las oligarquías terratenientes. 
era Evo Morales con la frase "Bolivia unida a las autonomías", mientras que la campaña del No proponía "No a la constitución de la división", incluso la Congregación de Evangélicos en Bolivia se sumaron a la campaña a través de mensajes en los que decían que votar Sí por la Constitución era darle la espalda a Jesucristo, y se manifestaban diciendo "Elige a Dios- Vota NO" (Asociación de Iglesias Cristianas Unidas 8 de enero 2009).

De acuerdo con el Informe "Misión de observación electoral de la Unión Europea" los medios de comunicación privados eran especialmente favorables a la campaña por el NO, en tanto que los medios de comunicación estatales reflejaron un sesgo a la campaña del "Sí", por lo que no fue equilibrada la información presentada al electorado. En el mismo informe se destaca que durante la campaña hubo un uso generalizado de propaganda institucional, principalmente a través de medios de comunicación electrónicos (televisivos y radial). Este hecho pudiera interpretarse como un uso indebido de recursos estatales (2009:5)

Aunque en la campaña electoral el MAS manifestaba su apoyo a las autonomías de las comunidades indígenas, semanas antes de la celebración del referéndum, el partido oficialista se postuló por el "no", argumentado que "los partidos tradicionales y las oligarquías que habían perdido el poder político intentaban mantener sus privilegios desde las prefecturas" (Torrico, 2006:5). Tanto Morales como el Vicepresidente Álvaro García Linera participaban activamente en la campaña a través de mítines, el cierre de campaña fue en los departamentos de Cochabamba y La Paz el 22 de enero de 2009, el mensaje de Morales era contundente, con la aprobación de la Nueva Constitución se refundaría Bolivia y se acabaría con el neoliberalismo.

La campaña por el "NO" organizó un cierre de campaña en Santa Cruz, en la cual participaron los Prefectos de Santa Cruz, Beni, Tarija y Chuquisaca, al cierre de campaña, el mensaje de la oposición era "Bolivia SÍ. Venezuela NO", Sí a la Democracia y No a la Dictadura. Las profundas líneas de fractura que se habían dibujado en el panorama político desde el año 2000 tuvieron como consecuencia una profunda polarización en la política. A pesar de la victoria de Morales en las urnas, ésta no terminó con las divisiones políticas y sociales, incluso éstas se tornaron mucho más profundas. El atractivo 
del cambio de gobierno, fue que éste planteaba la posibilidad de reestructurar al sistema político, que se encontraba debilitado desde 2003, y poder establecer reformas políticas que encaminarán al país a solucionar los problemas de desigualdad social persistentes en la sociedad boliviana.

\section{Resultados del referendo}

Los resultados del referéndum ratificaron la Nueva Constitución del Estado con una participación política histórica, pues el 90.2 por ciento de los electores bolivianos asistieron a las urnas. El SÍ tuvo el 61.4 por ciento de la votación. Los votos en contra sumaron 38.57 por ciento. A continuación se presentan los resultados en los departamentos.

\section{Cuadro 7. Votación por departamentos Referendo Nacional Constituyente}

\begin{tabular}{|c|c|c|c|}
\hline Departamentos & Votación Sí & Votación No & Diferencia \\
\hline La Paz & $\mathbf{7 8 . 1 2}$ & 21.88 & 56.24 \\
\hline Oruro & $\mathbf{7 3 . 6 8}$ & 26.32 & 47.32 \\
\hline Cochabamba & $\mathbf{6 4 . 9 1}$ & 35.09 & 29.82 \\
\hline Chuquisaca & $\mathbf{5 1 . 5 4}$ & 48.46 & 3.08 \\
\hline Potosí & $\mathbf{8 0 . 0 7}$ & 19.93 & 60.14 \\
\hline Tarija & 43.34 & $\mathbf{5 6 . 6 6}$ & 13.32 \\
\hline Santa Cruz & 34.75 & $\mathbf{6 5 . 2 5}$ & 30.5 \\
\hline Beni & 32.67 & $\mathbf{6 7 . 3 3}$ & 34.66 \\
\hline Pando & 40.96 & $\mathbf{5 9 . 0 4}$ & 18.08 \\
\hline
\end{tabular}

Fuente: Elaboración propia de la Corte Nacional Electoral

De acuerdo a Fernando Mayorga, los dos polos antagónicos estaban (y siguen estando) organizados en torno a diversas líneas de conflicto (clivajes) como son: estado-mercado (nacionalismo-liberalismo) étnico-cultural (indígenas-criollos), y regional (oriente-occidente); estas líneas de conflicto "que ponen en juego: asuntos económicos, territoriales y étnicos culturales" (Mayorga, 2008:25), estos polos antagónicos son muy visibles al observar los resultados, sólo en el departamento de Chuquisaca los resultados estuvieron cerrados, mientras que en algunos departamentos como Potosí, en donde 
existe un número importante de población indígena el voto favor de la propuesta de Morales fue del 80 por ciento, en Santa Cruz, departamento del oriente boliviano el voto detractor de la propuesta del presidente fue de poco más del 60 por ciento.

En ese sentido, el triunfo del Presidente Evo Morales, en los tres primeros referendums, puede ser explicado por la estrategia política en donde contaba con el suficiente apoyo popular, con poderes partidarios en el Congreso y con una economía estable. Pese a que el Presidente logró el triunfo, alrededor de los ejercicios de democracia directa impulsados por el líder del MAS surgieron opositores, quienes emprendieron una campaña activa en contra de los MDD impulsados por el oficialismo. Aunque en los tres mecanismos de democracia directa se impusó la propuesta presidencial, el proceso fue competitivo y surgió una nueva oposición a cargo de los prefectos departamentales (veáse cuadro 2). El eventual triunfo de Morales durante su estancia como presidente le dieron el apoyo pupular para presentarse como candidato a una tercera elección presidencial.

\section{El camino a un cuarto referendúm}

Evo Morales se presentó a una tercera candidatura en 2014. Para entender cómo es que el presidente se presentó como candidato nuevamente, es preciso señalar que la constitución de 2009 en su artículo 168 constitucional establecía los siguiente "El periodo de mandato de la Presidenta o del Presidente y de la Vicepresidenta o del Vicepresidente del Estado es de cinco años, y pueden ser reelectas o reelectos por una sola vez de manera continua", en la misma Constitución se incorporó una Disposición Transitoria Primera de la Constitución que establecía lo siguiente: "Los mandatos anteriores a la vigencia de esta Constitución serán tomados en cuenta a los efectos del cómputo de los nuevos periodos de funciones" (Constitución Nacional de Bolivia, 2009).

Al acercarse el término del segundo periodo presidencial, el tema de la reelección estaba presente en los medios, hasta ese momento Morales no se había pronunciado, por lo que resultó inesperado el hecho de que en febrero de 2013 surgiera la iniciativa legislativa desde el Senado, en donde legisladores oficialistas elaboraron un proyecto titulado "Ley de aplicación 
normativa" cuyo propósito de este tipo de Ley "se presentaba ante la existencia de normas constitucionales que, siendo claras, deben ser desarrolladas por el legislador usando los grandes principios y valores del derecho, como la aplicación de la norma especial sobre la norma general, la aplicación de los principios y valores de la democracia representativa, los principios y valores que hacen al Derecho Internacional, etc."(sic) Para Alán Vargas este argumento era en realidad el siguiente:

La pretensión última del proyecto legislativo, no era simplemente desarrollar normas constitucionales, sino únicamente habilitar -de manera subrepticia y por vía de una Ley interpretativa-, la segunda reelección presidencial del gobernante de turno, a pesar de la existencia de un mandato imperativo en sentido contrario, establecido por la misma Constitución Política del Estado, refrendada por el pueblo boliviano en el año 2009 (Vargas, 2015:448).

La Corte Suprema en abril de 2013 emitió un veredicto en el que determinó que el primer periodo presidencial de Evo Morales ya no contaría como periodo previo, ya que la Constitución había sido reformada y por tanto se habilitó la posibilidad de que el presidente volviera a contender formalmente en las elecciones de 2014. El Tribunal Supremo Electoral dio a conocer las fechas formales para las elecciones presidenciales. La primera vuelta se celebraría el 12 de octubre de 2014 y la segunda vuelta, en caso de requerirse se llevaría a cabo en diciembre.

Evo Morales se presentó como candidato del MAS para contender a la elección presidencial de 2014, sus oponentes principales eran el candidato Samuel Doria Medina candidato de Unidad Demócrata, el empresario Jorge Quiroga del Partido Demócrata Cristiano y Fernando Vargas del Partido Verde de Bolivia. La contienda electoral dio el triunfo en una primera vuelta a Evo Morales, quien obtuvo el 61.3 por ciento de la votación, Samuel Doria quedó en segundo lugar con el 24.2 por ciento. Bajo estas condiciones no fue necesario convocar a una segunda vuelta, toda vez que Morales obtuvo la mayoría absoluta de la votación. 
Sobre las condiciones generales de la convocatoria, las líneas de conflicto

La iniciativa para la celebración del referendo sobre la reelección presidencial llegó una semana antes de que se celebrara el referéndum sobre los estatutos autonómicos de cinco departamentos (La Paz, Oruro, Potosí, Chuquisaca y Cochabamba) y cartas orgánicas en las comunidades indígenas de Totora Marka y Charagua, los estatutos y cartas orgánicas regularían el funcionamiento de los gobiernos respecto al Estado y están sustentados bajo la constitución de $2009 .^{6}$

El referéndum se llevó a cabo el domingo 20 de septiembre, este antecedente es importante de considerar, pues es el primer llamado de atención sobre un posible rechazo de la población al mandato de Evo Morales y porque en diversos medios bolivianos fue concebido como un ejercicio del poder ejecutivo para medir el poder de convocatoria del presidente en el departamento de La Paz.

Los resultados fueron desfavorecedores al oficialismo que buscaba que la población votara por el Sí, en tanto que la oposición en los departamentos se postulaba por el No. Entre los argumentos de la oposición se encontraba el hecho de que los estatutos y cartas orgánicas eran elementos difíciles de comprender y que las personas difícilmente podrían saber qué era lo que se estaba votando. Finalmente, los resultados terminaron siendo catastróficos para el oficialismo.

6 La Constitución de 2009 estableció con "igual jerarquía", autonomías departamentales, provincias regionales y las comunidades indígenas con facultades administrativas y legislativas. 
Cuadro 8. Porcentaje de los resultados sobre el referendo de los estatutos autonómicos 2015

\begin{tabular}{|c|c|c|}
\hline Departamentos & SÍ & NO \\
\hline Cochabamba & 35.3 & 56.65 \\
\hline Chuquisaca & 38.64 & 52.13 \\
\hline La Paz & 29.32 & 62.47 \\
\hline $\mathrm{Fu}$ & 23.89 & 68.07 \\
\hline Potosí & 29.04 & 61.94 \\
\hline
\end{tabular}

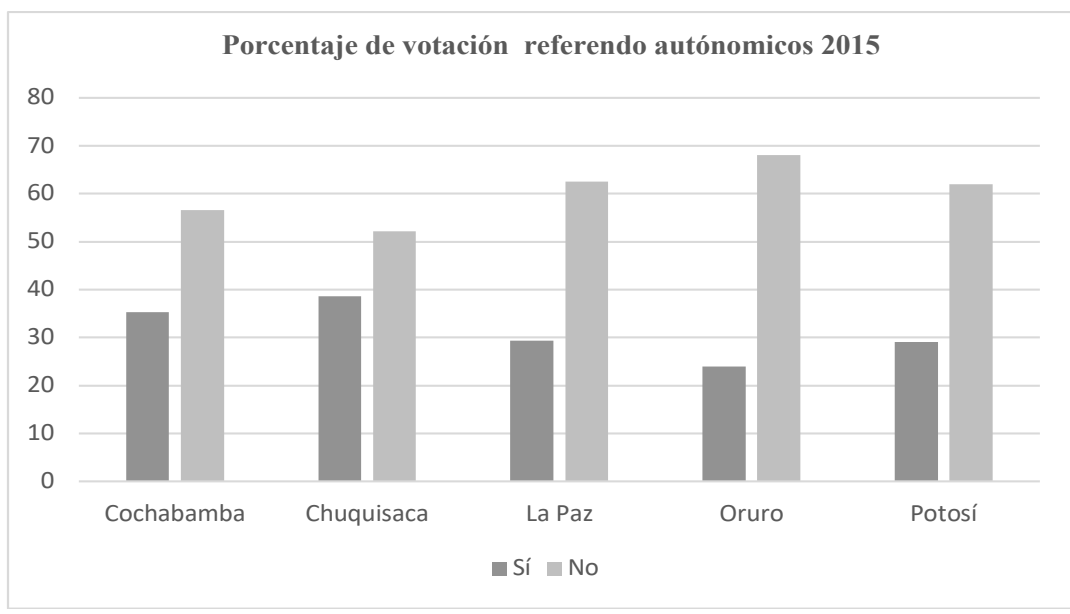

Fuente: Elaboración propia con datos del Órgano Plurinacional Electoral

El día 17 de septiembre, justo unos días antes de celebrarse los referéndums autonómicos, es que sindicatos de obreros, cocaleros e indígenas afines al gobierno presentaron un proyecto de ley para una nueva reelección del presidente Evo Morales por cinco años más (2020-2025), esta iniciativa debía pasar por el Congreso antes de un referendo para su aprobación o rechazo. Uno de los aspectos más significativos de la presentación de la iniciativa es que estuvo acompañada por una marcha que transitó por varias calles de La 
Paz hasta llegar al Congreso (véase La Jornada, 17 de septiembre 2015). De forma general los medios impresos, nacionales e internacionales daban cuenta del apoyo de sindicatos, organizaciones populares y movimientos sociales eran quienes se postulaban sobre la reelección, y se ponía énfasis que este proceso de referéndum estaría impulsado desde la población y no desde el poder ejecutivo. Es notable que en esta ocasión fueran organizaciones quienes solicitaran la reforma constitucional, y tiene cierta justificación en tanto que se piensa que hubiera sido un error estratégico impulsar el referéndum desde el poder presidencial, sobre todo después de la modificación constitucional de 2013. El hecho de que sean organizaciones sociales quienes impulsen el proceso de modificación de la ley para que sean posible dos reelecciones continuas resultaba una jugada estratégica por parte del Presidente.

Toda vez que los movimientos sociales y sindicatos entregaron la propuesta al poder legislativo, la iniciativa comenzó a discutirse en el pleno de la Asamblea Legislativa, incluso el propio presidente de Senado, el oficialista Alberto González declaró que la propuesta sería analizada y aprobada con celeridad (La Jornada 17 de septiembre de 2015). Con el congreso controlado por el MAS todo parecía viable, aunque la oposición se manifestó en contra de inmediato, sobre todo el gobernador de Santa Cruz, Rubén Costas y Samuel Doria Medina ex candidato presidencial. Para el día 26 de septiembre, diez días después de haber presentado la iniciativa, la Asamblea Legislativa Plurinacional de Bolivia aprobó la Ley de Reforma Parcial Constitucional, la modificación del artículo 168 fue aprobada con 113 votos a favor y 44 en contra (véase Correo del Sur 26 de septiembre de 2015). La oposición del Partido Demócrata Cristiano,principalmente, había solicitado que la ciudadanía organizara una vigilia que asegurara que el debate sobre la reforma fuera televisado. Una vez acordada la reforma, el Tribunal Superior Electoral (TSE) procedió a la observación de las modificaciones del procedimiento para el referéndum. El TSE hizo ajuste a la pregunta y volvió a la Asamblea para su aprobación, la pregunta sugerida por la Asamblea contemplaba nombrar particularmente al poder ejecutivo actual, además de no dar claridad sobre los periodos presidenciales, por lo que el TSE elaboró la siguiente modificación en donde se elimina la frase "los actuales mandatarios" además de 
incluir un párrafo como aclaración informativa: "Por disposición de la Ley de Reforma Parcial a la Constitución Política del Estado, se considera como primera reelección al periodo 2015-2020 y la segunda reelección 2020-2025". A continuación las dos preguntas:

\section{Cuadro 9}

\begin{tabular}{|c|c|}
\hline Propuesta legislativo & Pregunta sugerida por el TSE \\
\hline $\begin{array}{l}\text { “Está usted de acuerdo con la reforma del } \\
\text { artículo } 168 \text { de la Constitución Política del } \\
\text { Estado para permitir que la Presidenta o } \\
\text { Presidente y la Vicepresidenta o el Vicepre- } \\
\text { sidente del Estado puedan ser reelectas o } \\
\text { reelectos por dos veces de manera continua, } \\
\text { lo que habilitaría la candidatura de los actua- } \\
\text { les mandatarios por el periodo } 2020-2025 ?\end{array}$ & $\begin{array}{l}\text { ¿Está usted de acuerdo con la reforma del } \\
\text { artículo } 168 \text { de la Constitución Política del } \\
\text { Estado para permitir que la Presidenta o } \\
\text { Presidente y la Vicepresidenta o el Vicepre- } \\
\text { sidente del Estado puedan ser reelectas o } \\
\text { reelectos por dos veces de manera continua? }\end{array}$ \\
\hline
\end{tabular}

Fuente: Elaboración propia con datos del periódico La Razón de Bolivia del 10 de octubre de 2015.

Las modificaciones del TSE no fueron bien recibidas por el poder Legislativo, ni por el propio Vicepresidente. El presidente del Senado señaló en su momento que la nueva pregunta sugerida por el TSE "es más larga y menos concisa". Además, aseguró que es un "exceso de susceptibilidad de parte del TSE" el prescindir de la puntualización "actuales mandatarios" (Diario La razón 10 de octubre de 2015). Por otra parte el señalamiento hecho por el TSE sobre cuál era el primer periodo considerado como primera reelección obedecía a señalamientos previos hechos por el Senador Óscar Ortiz de Unidad Demócrata (UD) quien había señalado que la redacción de la pregunta posibilitaba una tercera postulación. De forma inmediata García Linera, vicepresidente de Bolivia, decidió convocar al pleno legislativo para que fueran evaluadas las sugerencias del TSE. Finalmente la pregunta que se presentó ante el electorado fue la sugerida por el TSE.

Pese a las manifestaciones de la oposición, el día 5 de noviembre 170 
de 2015 la ley de convocatoria al referendo referido a la reforma de la Constitución Política del Estado sobre la reelección presidencial había sido aprobada con 113 votos a favor y 43 en contra. Desde que fue aprobada la reforma con los dos tercios de la Asamblea Plurinacional Legislativa, los partidos de la oposición pusieron de manifiesto que se exigiría al Tribunal Superior Electoral la vigilancia de la campaña del referéndum, incluso se planteó la necesidad de una Reforma Electoral para suspender las acciones de gobierno que pudieran ocuparse como campaña, para ello tendría que eliminarse de los promocionales la frase "gestión de gobierno" (véase Correo del Sur 24 de septiembre 2015).

\section{Referéndum para la Reelección presidencial}

Las campañas para la definición del referendo comenzaron el día 14 de diciembre de 2015, sin embargo, es notable que desde la discusión sobre la ley de convocatoria los diputados vestían con playeras que tenían el SÍ o el NO, además de que desde las discusiones del pleno existía la consigna de posicionarse claramente. Dentro de los argumentos principales de la oposición política de Bolivia era que la adaptación a la ley era una "triquiñuela" porque se adaptaba a las necesidades de una sola persona. La campaña por el NO estuvo presentada mediáticamente como una movilización ciudadana, incluso con asociaciones jóvenes y líderes de la izquierda boliviana, más que una campaña liderada por partidos (Pablo Stefanoni, 2016). ${ }^{7}$

Evo Morales comenzó su campaña por el referéndum en Sucre, durante su discurso enunció que su reelección es "un instrumento político de liberación del pueblo boliviano", entre los logros más significativos que se destacaron la nacionalización de los hidrocarburos, el crecimiento económico, y la disminución de la pobreza. El presidente denunció una supuesta guerra sucia por parte de la oposición y la lucha a la corrupción que supuestamente defienden sus opositores (véase Nodal: 14 de diciembre de 2015).

\footnotetext{
7 Los partidos que se postularon por el NO fueron los siguientes Movimiento Demócrata Social (MDS), Frente de Unidad Nacional (UN) Comité Cívico Potosinista (COMCIPO) Soberanía y Libertad (SOL.BO), Frente Revolucionario de Izquierda (FRI), Movimiento Nacionalista Revolucionario (MNR)Partido Demócrata Cristiano (PDC). Las asociaciones civiles por el NO fueron: Me comprometo, Bolivia dice NO, Todos podemos ser presidente.
} 
El referéndum se celebró el domingo 21 de febrero de 2016 con un resultado en contra a la propuesta de reelección de Morales y del Vicepresidente García Linera (véase cuadro 4), aunque la diferencia de puntos fue menos de tres puntos porcentuales, es notable que Evo Morales no ganó en ninguno de los departamentos, y que la tendencia fue polarizada en todos los departamentos (véase cuadro 10).

Cuadro 10. Resultados generales del Referéndum Constitucional 2016

\begin{tabular}{|c|c|c|}
\hline Propuesta & Votos & \% \\
\hline No & $2,682,517$ & 51.3 \\
\hline Sí & $2,504,919$ & 48.7 \\
\hline Blancos & 68.845 & \\
\hline Nulos & 193,422 & \\
\hline Total & $5,490,919$ & 84.45 \\
\hline
\end{tabular}

Refeéndum constitucional 2016. Resultados por departamento

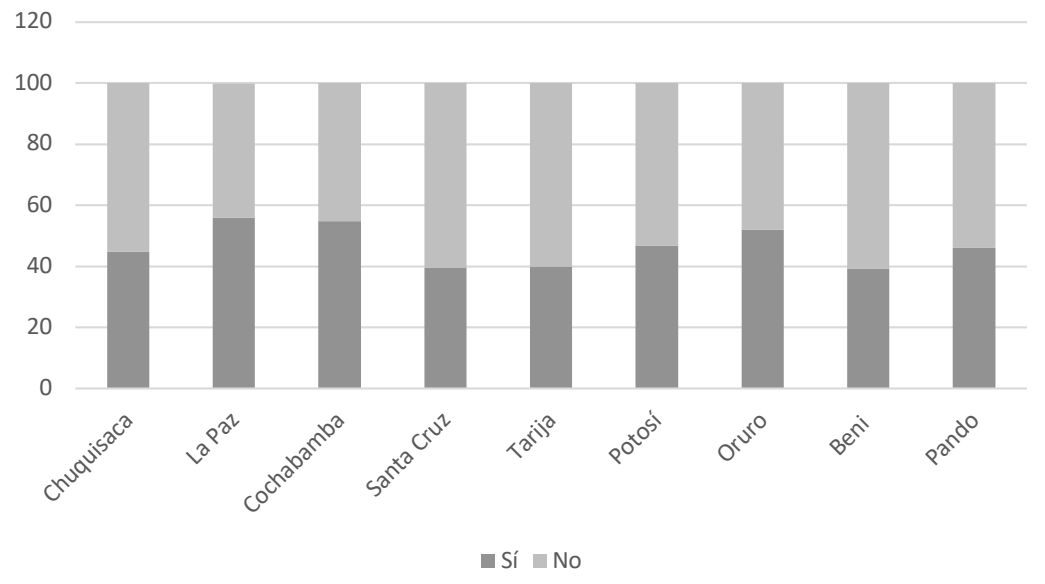




\section{Cuadro 11}

\begin{tabular}{|c|c|c|}
\hline Departamentos & SÍ & No \\
\hline Chuquisaca & 44.8 & 55.2 \\
\hline La Paz & 55.8 & 44.1 \\
\hline Cochabamba & 54.9 & 45.1 \\
\hline Santa Cruz & 39.6 & 60.4 \\
\hline Tarija & 39.9 & 60.1 \\
\hline Potosí & 46.8 & 53.2 \\
\hline Oruro & 52 & 48 \\
\hline Beni & 39.3 & 60.7 \\
\hline Pando & 46 & 54 \\
\hline
\end{tabular}

\section{Conclusiones}

En su libro World Wide Democracy, David Altman destacó que la actitud plebiscitaria de los presidentes latinoamericanos no obedeció en la mayoría de los casos al objetivo de proponer la participación ciudadana, como supone la democracia directa, sino más bien la convocatoria de los referéndums tuvo como meta la realización de cambios constitucionales o la retención del poder y no para la promoción de la participación ciudadana. Sin embargo, también el propio Altman señala que "una atmosfera plebiscitaria en un país no es necesariamente la propensión megalómana de un líder en específico, pues finalmente los líderes tienden a utilizar todas las prerrogativas a su disposición para avanzar en sus agendas" (Altman, 2011:110). Esta investigación apunta a reconocer que pese a la propensión plebiscitaria por parte del ex presidente Evo Morales hay también una serie de factores que contribuyeron al fracaso, como es la activación de contrapesos por parte de la oposición que puede articularse desde las instituciones o desde la ciudadanía.

Pese a que la estrategia presidencial de Evo Morales estaba fundamentada en su popularidad, esta agudización del clivaje etnico puso en evidencia que no bastaba el apoyo popular, incluso en los bastiones electorales del presidente, pues era notable que existía elecciones competitivas y poca certeza sobre las instituciones involucradas. 
Estrategia presidencial Evo Morales

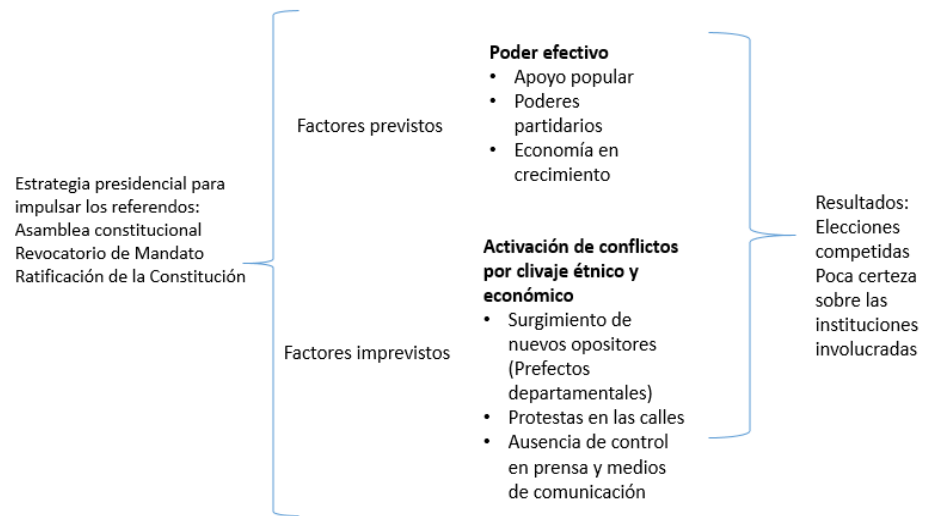

Fuente: Elaboración propia

Desde el año 2004 el pueblo boliviano ha sido convocado a votar siete ejercicios de referéndums, asimismo, en el periodo de 2005 a 2016 ha asistido a las urnas para votar al mismo presidente tres ocasiones. Si sumamos ambos ejercicios, el presidente Morales ha tomado participación y protagonismo en las urnas durante diez ocasiones. Y aunque se puede percibir cierto refinamiento en la estrategia presidencial sobre cómo usar el poder hegemónico que tiene como partido dentro de la Asamblea Plurinacional Electoral y con el grupo de organizaciones políticas simpatizantes con el MAS, además de la conquista de los espacios en medios de comunicación, que antes se consideraban abiertamente como enemigos del régimen. Lo cierto es que Morales perdió preeminencia en departamentos clave, como son La Paz, Oruro o Potosí.

Si analizamos a detalle los resultados por departamento podremos notar que desde 2005 a la fecha, el presidente Morales ha perdido una presencia significativa en el departamento de La Paz, asimismo es notable que aunque sigue teniendo fuerza en los departamentos con mayor 
presencia indígena como son Santa Cruz, Tarija y Potosí, lo cierto es que ahí se registró una mayor votación por el NO, esta tendencia de votación se observaba ya desde el referéndum sobre los estatutos autonómicos en 2015. El comportamiento electoral de Beni se ha mantenido constante, desde 2005, pues es el departamento en donde menos apoyo político tiene el MAS y de forma específica Evo Morales. Asimismo sucede con el departamento de Santa Cruz que también mantuvo constante en su desaprobación a la propuesta del líder cocalero.

\section{Cuadro 12. Balance de la estrategia presidencial en los referendums}

\begin{tabular}{|c|c|c|c|c|}
\hline $\begin{array}{l}\text { Mecanismo de } \\
\text { democracia } \\
\text { directa }\end{array}$ & $\begin{array}{l}\text { Fuerza política } \\
\text { del presidente }\end{array}$ & Contexto & $\begin{array}{l}\text { Control de } \\
\text { agenda }\end{array}$ & Resultado \\
\hline $\begin{array}{l}\text { Elección de la } \\
\text { asamblea consti- } \\
\text { tuyente }\end{array}$ & $\begin{array}{l}\text {-Elección presi- } \\
\text { dencial ganada } \\
\text { con la mayoría } \\
\text { absoluta } \\
\text {-Mayoría abso- } \\
\text { luta en Cámara } \\
\text { de Diputados, } \\
\text { segunda fuerza } \\
\text { en el Senado }\end{array}$ & $\begin{array}{l}\text {-Crecimiento } \\
\text { económico } \\
\text { positivo } \\
\text { - Apoyo al } \\
\text { gobierno } \\
\text { Más del } 50 \text { por } \\
\text { ciento de la } \\
\text { población }\end{array}$ & $\begin{array}{l}\text { Sin interven- } \\
\text { ción, } \\
\text { Apoyo calle- } \\
\text { jero }\end{array}$ & $\begin{array}{c}\text { Ganó la op- } \\
\text { ción presiden- } \\
\text { cial }\end{array}$ \\
\hline $\begin{array}{l}\text { Referéndum } \\
\text { revocatorio }\end{array}$ & $\begin{array}{l}\text {-Elección presi- } \\
\text { dencial ganada } \\
\text { con la mayoría } \\
\text { absoluta } \\
\\
\text {-Mayoría abso- } \\
\text { luta en Cámara } \\
\text { de Diputados, } \\
\text { segunda fuerza } \\
\text { en el Senado }\end{array}$ & $\begin{array}{l}\text {-Crecimiento } \\
\text { económico } \\
\text { positivo } \\
\text {-Apoyo al } \\
\text { gobierno } \\
\text { Más del } 60 \text { por } \\
\text { ciento de la } \\
\text { población }\end{array}$ & $\begin{array}{l}\text {-Señalamiento } \\
\text { CNE sobre } \\
\text { algunos linea- } \\
\text { mientos de la } \\
\text { pregunta, sin } \\
\text { embargo no } \\
\text { hubo un cam- } \\
\text { bio. }\end{array}$ & $\begin{array}{c}\text { Ganó la op- } \\
\text { ción presiden- } \\
\text { cial }\end{array}$ \\
\hline
\end{tabular}




\begin{tabular}{|c|c|c|c|c|}
\hline $\begin{array}{l}\text { Referéndum } \\
\text { constitucional }\end{array}$ & $\begin{array}{l}\text {-Elección presi- } \\
\text { dencial ganada } \\
\text { con la mayoría } \\
\text { absoluta } \\
\\
\text {-Mayoría abso- } \\
\text { luta en Cámara } \\
\text { de Diputados, } \\
\text { segunda fuerza } \\
\text { en el Senado }\end{array}$ & $\begin{array}{l}\text {-Crecimiento } \\
\text { económico } \\
\text { positivo } \\
\text { Apoyo al go- } \\
\text { bierno } \\
\text {-Más del } 50 \\
\text { por ciento de la } \\
\text { población }\end{array}$ & $\begin{array}{l}\text { Señalamiento } \\
\text { de la CNE que } \\
\text { suspendió el } \\
\text { referéndum por } \\
\text { considerarlo } \\
\text { ilegal, pero } \\
\text { con un amplio } \\
\text { apoyo callejero. }\end{array}$ & $\begin{array}{l}\text { Ganó la op- } \\
\text { ción presiden- } \\
\text { cial }\end{array}$ \\
\hline $\begin{array}{l}\text { Referéndum } \\
\text { cuarto periodo } \\
\text { presidencial } \\
\text { (reelección) }\end{array}$ & $\begin{array}{l}\text { Elección presi- } \\
\text { dencial ganada } \\
\text { con la mayoría } \\
\text { absoluta } \\
\text { Mayoría absoluta } \\
\text { en Cámara de } \\
\text { Diputados, se- } \\
\text { gunda fuerza en } \\
\text { el Senado }\end{array}$ & $\begin{array}{l}\text { Decrecimiento } \\
\text { económico } \\
\\
\text { Apoyo al } \\
\text { gobierno de } \\
\text { más del } 70 \text { por } \\
\text { ciento de la } \\
\text { población }\end{array}$ & $\begin{array}{l}\text { Modificación a } \\
\text { la pregunta } \\
\text { Escaso apoyo } \\
\text { callejero }\end{array}$ & $\begin{array}{l}\text { Perdió la } \\
\text { opción presi- } \\
\text { dencial }\end{array}$ \\
\hline
\end{tabular}

Hay una regularidad en los referéndums aquí expuestos, esta es que el predominio del poder ejecutivo se ha impuesto en el momento de impulsar las preguntas o las reglas para la celebración de referéndums, esta imposición se hace patente porque pese a los señalamientos de las autoridades electorales, $o$ de la oposición, en las resoluciones judiciales o de las autoridades electorales prevalece la posición oficial.

En ese sentido, el triunfo del Presidente Evo Morales en los tres primeros referendums puede ser explicado por la estrategia política en donde contaba con el suficiente apoyo popular, con poderes partidarios en el Congreso y con una economía estable. Pese a que el Presidente logró el triunfo, alrededor de los ejercicios de democracia directa impulsados por el líder del MAS surgieron opositores, quienes emprendieron una campaña activa en contra de los MDD impulsados por el oficialismo. Aunque en los tres mecanismos de democracia directa se impuso la propuesta presidencial, el proceso fue competido y surgió una nueva oposición a cargo de los prefectos departamentales. Mientras que en el cuarto referéndum el presidente dejó de contar con su base de apoyo popular. 


\section{Bibliografía}

Altman, David. (2011). Worldwide and democacy. New York. Cambridge University Press.

Altman, David. (2010). "Plebiscitos, referendos e iniciativas populares en América Latina: ¿mecanismos de control político o políticamente controlado?" Perfiles latinoamericanos 35, enero-julio 2010

(2016) "Votar hasta lograr el resultado", en El País, 8 de julio de 2016. http://internacional.elpais.com/internacional/2016/07/08/ actualidad/1467990346 626857.html

Amézquita Quintana, Constanza. (2008). "Fuerzas políticas movilizadas ante el referendo de 2003 en Colombia". Análisis Político, Número 63, 78-102

Barczak, Monica. (2001). "Representation by Consultation? The Rise of Direct Democracy in Latin America". Latin American Politics \& Society 43, núm. 3, pp. 37-59.

Basabe-Serrano, S., Pachano, S \& Mejía Acosta, A. (2017). "La democracia inconclusa: Derechos fundamentales, instituciones políticas y rendimientos gubernamentales en Ecuador (1979-2008)". http://www. scielo.cl. 25 Agosto 2017, Recuperado de: http://www.scielo.cl/scielo. php?script=sci arttext\&pid $=$ S0718-090X2010000100005

Bates, Robert H, Avner Greif, Margaret Levi, Jeant-Laurent Rosenthal and Barry Weingast (2000). "Tha Analytical Narrative Project", American Political Ressearch Review.

Breuer, Anita. (2008). "Policymaking by Referendum in Presidential Systems: Evidence from the Bolivian and the Colombian Cases", Latin American Politics \& Society 50, núm. 4, pp. 59-89.

Breuer, Anita. (2007) "Institutions of Direct Democracy and Accountability in Latin America's Presidential Democracies", Democratization 14, núm. 4, pp. 554-579. 
Clarence Walker Mark. (2003) The Strategic Use of Referendums: Power, Legitimacy, and Democracy. By New York: Palgrave Macmillan, 2003

Deheza Grace Ivana (2007) Bolivia 2006: -"Reforma estatal y construcción del poder" Especial, Pontificia Universidad Católica de Chile, Santiago Chile

Durán Martínez, Angélica. (2012) "Presidents, Political Parties and Referenda in Latin America," Comparative Political Studies 45:8 (August 2012)

Gamble, Barbara S., (1997), "Putting Civil Rights to a Popular Vote", American Journal of Political Science 41, núm. 1, pp. 245-269

Herrera Betancourt, P. (2011, Febrero, 23) Dictamen de constitucionalidad de referendo [PDF] Quito, Ecuador. Recuperado de: http://www.cpccs.gob.ec/docs/normativaDocs/811734.pdf

Lanzaro Jorge (2000) Tipos de presidencialismo y coaliciones políticas en América Latina, Buenos Aires, CLACSO

Lissidini Alicia (2008), "Democracia Directa en Venezuela", en Documento de trabajo Núm. 32, Escuela de Política y Gobierno, 8 de marzo de 2008 .

Mayorga, René (2001) "Presidencialismo parlamentarizado y gobiernos de coalición en Bolivia", en Lanzaro, Jorge (coord.) Tipos de presidencialismo y coaliciones en América Latina, Buenos Aires, EUDEBACLACSO.

Molina Fernando (2014) "La oposición boliviana entre "la política de la fe" y "la política del escepticismo", Nueva Sociedad 254, NoviembreDiciembre.

Romero Ballivián, Salvador (2007), _-'La elección presidencial del 18 de diciembre de 2005 en Bolivia"l, en Atlas electoral latinoamericano, La Paz. Bolivia, Corte Nacional Electoral de Bolivia 
(2014), "Diez desafíos de la Democracia boliviana, el panorama político para el periodo constitucional 2015-2020" en Journal de Comunicación Social, Año 2, Vol. 2, diciembre 2014, Universidad Católica Boliviana San Pablo.

(2019), Mandato y contingencia, estilo de gobierno de Evo Morales, La Paz Bolivia, FES, CESU-UMSS.

Soto Barrientos, Francisco (2013) "El referéndum en latinoamérica: un análisis desde el derecho comparado" Boletín Mexicano de Derecho Comparado, vol. XLVI, núm. 136, pp. 317-346 Universidad Nacional Autónoma de México Distrito Federal, México

Stefanoni Pablo (2010), “-Bolivia después de las elecciones: ¿adónde va el evismo?", en Nueva Sociedad No 228, julio-agosto de 2010, ISSN: 0251-3552, <www.nuso.org>.

Welp Yaninna (2010), “-El referendo en América Latina Diseño institucionales y equilibrios de poder" en Nueva Sociedad, $\mathrm{N}^{\mathrm{O}} 228$, julioagosto de 2010, ISSN: 0251-3552, <www.nuso.org>.

Vargas Velásquez, Alejo. (2004). "El gobierno de Álvaro Uribe, proyectos y resultados". Política, estrategias y doctrinas". Nueva Sociedad, 192, julio-agosto 2004.

Zovatto Daniel (2008), "Las instituciones de Democracia Directa" en: Diether Nohlen, Daniel Zovatto (Compiladores), Tratado de derecho electoral comparado de América Latina, México, Fondo de Cultura Económica, segunda edición, p.294

\section{Siglas}

AC Asamblea Constituyente

ADN Acción Democrática Nacionalista. Partido de derecha fundado por Hugo Banzer

AP Acuerdo Patriótico. Nombre del pacto gubernamental de 1989 
AS Alianza Social. Agrupación política que contendió en las elecciones en 2009

ASP Asamblea por la Soberanía de los Pueblos

BSD Bolivia Social Demócrata. Agrupación política que contendió en las elecciones en 2009

COB Central Obrera Boliviana

CONDEPA Conciencia de Patria. Partido político de Carlos Palenque

CEPB Confederación de Empresarios de Bolivia

CSUTB Central Única de Trabajadores Campesinos de Bolivia

FMI Fondo Monetario Internacional

IPSP Instrumento Político por la Soberanía de los Pueblos

LRET Ley de Régimen Electoral Transitoria

MAS Movimiento al Socialismo. Partido político dirigido por Evo Morales

MBL Movimiento Bolivia Libre

MIR Movimiento de Izquierda Revolucionaria. Partido liderado Jaime Paz Zamora

MIP Movimiento Indio Pachakuti. Partido de Felipe Quispe 181

MNR Movimiento Nacional Revolucionario. Partido político dirigido por Víctor Paz Estenssoro

MUSPA Movimiento Unidad Social Patriótica Agrupación política que contendió en las elecciones en 2009

NFR Nueva Fuerza Republicana. Partido político dirigido por Manfred Reyes Villa 
NPE Nueva Política Económica

PODEMOS Poder Democrático Social. Agrupación política fundada por Jorge Quiroga PPB-CN Frente electoral compuesto por Plan Progreso para Bolivia y Convergencia Nacional

PULSO Pueblos por la Libertad y la Soberanía. Agrupación política que contendió en las elecciones en 2009

UCS Unión Cívica Solidaridad. Partido político fundado por Max Fernandez.

UDP Unión Democrática Popular. Primera coalición ganadora en las elecciones de 1982 UN Unidad Nacional. Agrupación política fundada por Samuel Doria Medina

UN-CP Frente electoral integrado por Unidad Nacional y la agrupación Consenso Popular 